Yasri, P., and Mancy, R. (2016) Student positions on the relationship between evolution and creation: what kinds of changes occur and for what reasons? Journal of Research in Science Teaching, 53(3), pp. 384-399.

There may be differences between this version and the published version. You are advised to consult the publisher's version if you wish to cite from it.

This is the peer reviewed version of the following article: Yasri, P., and Mancy, R. (2016) Student positions on the relationship between evolution and creation: what kinds of changes occur and for what reasons? Journal of Research in Science Teaching, 53(3), pp. 384-399, which has been published in final form at http://dx.doi.org/10.1002/tea.21302. This article may be used for non-commercial purposes in accordance with Wiley Terms and Conditions for Self-Archiving.

http://eprints.gla.ac.uk/112821/

Deposited on: 26 November 2015

Enlighten - Research publications by members of the University of Glasgow http://eprints.gla.ac.uk 
Running head: Student positions on evolution and creation

\title{
Student positions on the relationship between evolution and creation: what kinds of changes occur and for what reasons?
}

\author{
Pratchayapong Yasri $^{1}$ and Rebecca Mancy ${ }^{2,3}$ \\ ${ }^{1}$ Institute for Innovative Learning, Mahidol University, Thailand \\ ${ }^{2}$ School of Education, College of Social Sciences, University of Glasgow, UK \\ ${ }^{3}$ Institute of Biodiversity, Animal Health and Comparative Medicine, College of Life \\ Sciences, University of Glasgow, UK
}

\begin{abstract}
Student positions on the relationship between biological evolution and divine creation have been examined in a range of contexts, and although there is evidence that students can change their position on the relationship over a period of study, these changes have not been well characterised or explained in a quantitative manner. To investigate student changes in position on the relationship between evolution and creation, we synthesised existing literature to develop a new research tool covering eight positions and a question probing reasons for changes in position. Buddhist and Christian high school students undertaking a course on evolution at a Christian school in Thailand $(\mathrm{N}=125$, mean age 17.6) responded to a survey to elicit their positions before and after course and reasons for any changes. Analysis revealed that a high proportion of students underwent a change in position, primarily towards increasing acceptance of evolution, a trend that was clearest among Christian students. Participants reported that these changes were influenced by changes in their understanding of the evidence for evolution and of ways of relating science and religion, but not in changes in their religious beliefs. The study shows that the tool is effective for detecting changes in position and eliciting key reasons for these changes. Moreover, it points to the importance during evolution education of focusing on the evidence for evolution and the relationship between science and religion.
\end{abstract}

Keywords: positions, evolution, creation, changes, reasons 
Student positions on evolution and creation

\section{Introduction}

The relationship between the scientific explanation of biological evolution and the biblical account of divine creation is generally perceived as one of dichotomy (Alexander, 2009). However, like the complexity apparent in the relationship between science and religion (Yasri, Arthur, Smith, \& Mancy, 2013), individuals' understandings of the relationship between evolution and creation ${ }^{1}$ often go beyond the black-and-white and have been classified into ranges of positions by several different authors (Brem, Ranney, \& Schindel, 2003; Collins, 2006; Scott, 2005; Verhey, 2005).

In the educational arena, if it were possible to identify a range of positions on the relationship between evolution and creation, this could be helpful to learners and teachers. It might be useful for them to appreciate that there are positions that do not require rejecting religious beliefs in a Creator God but nonetheless permit a scientific understanding of evolution (Smith, 2010). In addition, being aware of student positions is important for the development of effective teaching approaches and learning materials. This knowledge should allow teachers to anticipate how students are likely to integrate religious beliefs in divine creation with their knowledge of evolution. In this study, we developed a research tool covering a range of possible positions that individuals might take on the relationship between evolution and creation. We used this tool to investigate changes between the positions taken by high school students before and after a course on evolution. We also explored the reasons given by the students as explanations for any reported change in their own position.

\section{The spectrum of positions and tool development}

In order to develop a spectrum of positions on the relationship between evolution and creation, we compared and synthesised four existing categorisations from the literature (Brem et al., 2003; Collins, 2006; Scott, 2005; Verhey, 2005). Although there is clear overlap between these categorisations, some positions are present in one, but excluded from others. In addition, different terminologies are used to explain similar positions, as shown

\footnotetext{
${ }^{1}$ Note that we distinguish between views of the more general relationship between science and religion, and positions on the more specific relationship between evolution and creation (Yasri et al., 2013; Yasri \& Mancy, 2014)
} 
Student positions on evolution and creation

in Table 1. Through careful reading of the descriptions of the positions, we compared and contrasted these in an iterative manner to develop a unified framework in which eight positions on the relationship between evolution and creation are included: literal creationism, higher genera (of animals) created, humans only created, progressive creation, theistic evolution, deistic evolution, agnostic evolution and atheistic evolution. The outcome of this analysis is shown in Table 1, and descriptions of each position provided in Table 2.

Table 1: Positions on the relationship between evolution and creation in the literature and in this study.

\begin{tabular}{|c|c|c|c|c|}
\hline $\begin{array}{l}\text { Positions } \\
\text { employed in } \\
\text { this study }\end{array}$ & $\begin{array}{l}\text { Scott } \\
(2005)\end{array}$ & $\begin{array}{c}\text { Brem et al. } \\
\text { (2003) }\end{array}$ & $\begin{array}{l}\text { Verhey } \\
\text { (2005) }\end{array}$ & $\begin{array}{l}\text { Collins } \\
\text { (2006) }\end{array}$ \\
\hline $\begin{array}{c}\text { Literal } \\
\text { creationism }\end{array}$ & $\begin{array}{l}\text { Young earth } \\
\text { creationism }\end{array}$ & $\begin{array}{c}\text { Strong } \\
\text { creationist }\end{array}$ & $\begin{array}{c}\text { Literal } \\
\text { creationist }\end{array}$ & Creationism \\
\hline $\begin{array}{c}\text { Higher genera } \\
\text { created }\end{array}$ & - & - & \multirow{2}{*}{$\begin{array}{l}\text { Young earth } \\
\text { creationist }\end{array}$} & - \\
\hline $\begin{array}{c}\text { Humans only } \\
\text { created }\end{array}$ & - & $\begin{array}{c}\text { Human-only } \\
\text { creationist }\end{array}$ & & - \\
\hline $\begin{array}{c}\text { Progressive } \\
\text { creation }\end{array}$ & $\begin{array}{c}\text { Old earth } \\
\text { creationism }\end{array}$ & - & $\begin{array}{c}\text { Progressive } \\
\text { creationist/ } \\
\text { Intelligent } \\
\text { design } \\
\end{array}$ & - \\
\hline $\begin{array}{c}\text { Theistic } \\
\text { evolution }\end{array}$ & \multirow{2}{*}{$\begin{array}{c}\text { Theistic } \\
\text { evolutionism }\end{array}$} & Interventionist & - & $\begin{array}{l}\text { Theistic } \\
\text { evolution }\end{array}$ \\
\hline $\begin{array}{c}\text { Deistic } \\
\text { evolution }\end{array}$ & & $\begin{array}{c}\text { Theistic } \\
\text { evolutionist }\end{array}$ & $\begin{array}{c}\text { Theistic } \\
\text { evolutionist }\end{array}$ & $\begin{array}{c}\text { Deistic } \\
\text { evolution }\end{array}$ \\
\hline $\begin{array}{l}\text { Agnostic } \\
\text { evolution }\end{array}$ & $\begin{array}{c}\text { Methodologica } \\
\text { l naturalism }\end{array}$ & - & $\begin{array}{l}\text { Nontheistic } \\
\text { evolutionist }\end{array}$ & $\begin{array}{l}\text { Agnostic } \\
\text { evolution }\end{array}$ \\
\hline $\begin{array}{l}\text { Atheistic } \\
\text { evolution }\end{array}$ & $\begin{array}{c}\text { Philosophical } \\
\text { naturalism }\end{array}$ & $\begin{array}{l}\text { Nontheistic } \\
\text { evolutionist }\end{array}$ & $\begin{array}{c}\text { Atheistic } \\
\text { evolutionist }\end{array}$ & $\begin{array}{l}\text { Atheistic } \\
\text { evolution }\end{array}$ \\
\hline
\end{tabular}

Note. Use of '-ism', '-istic' and '-ist' as in the original articles.

In the development of the data collection tool, we first needed to develop descriptions of the positions that would be appropriate for empirical purposes. The 
Student positions on evolution and creation

descriptions of five of these positions were directly taken from the categorical statements proposed by Brem et al. (2003) because of their simplicity, success in empirical use and availability. The additional three positions were drawn from the other listed sources and rewritten to make them consonant with the style of those in Brem et al. (2003). All statements used in the study reported here are shown in Table 2.

Table 2: Positions on the relationship between evolution and creation, with descriptions used in the empirical study described here

\begin{tabular}{|c|l|}
\hline Positions & \multicolumn{1}{c|}{ Descriptions } \\
\hline $\begin{array}{c}\text { Literal } \\
\text { creationism }\end{array}$ & $\begin{array}{l}\text { All forms of life were first brought into being by a deity in more or less } \\
\text { their present form at the same time. }\end{array}$ \\
\hline $\begin{array}{c}\text { Higher } \\
\text { genera } \\
\text { created }\end{array}$ & $\begin{array}{l}\text { Some forms of life evolved from earlier forms created by a deity, but } \\
\text { higher taxonomical species such as reptiles, birds and mammals were } \\
\text { created in more or less their present form. }\end{array}$ \\
\hline $\begin{array}{c}\text { Humans only } \\
\text { created }\end{array}$ & $\begin{array}{l}\text { Some forms of life evolved from earlier forms created by a deity, but } \\
\text { human beings were created in more or less their present form. }\end{array}$ \\
\hline $\begin{array}{c}\text { Progressive } \\
\text { creation }\end{array}$ & $\begin{array}{l}\text { All forms of life were gradually created over time by a deity in more or } \\
\text { less their present form. }\end{array}$ \\
\hline $\begin{array}{c}\text { Theistic } \\
\text { evolution }\end{array}$ & $\begin{array}{l}\text { All forms of life evolved from earlier forms, but a deity intervenes from } \\
\text { time to time to shape or override the evolutionary processes. }\end{array}$ \\
\hline $\begin{array}{c}\text { Deistic } \\
\text { evolution }\end{array}$ & $\begin{array}{l}\text { All forms of life evolved from earlier forms, but life and evolution were } \\
\text { first set in motion by a deity and then left running without any } \\
\text { additional intervention. }\end{array}$ \\
\hline $\begin{array}{c}\text { Agnostic } \\
\text { evolution }\end{array}$ & $\begin{array}{l}\text { Life emerged from non-living particles and then all current forms } \\
\text { evolved from these earlier forms. A deity may exist, however, this is } \\
\text { out of scope of evolutionary theory. }\end{array}$ \\
\hline $\begin{array}{l}\text { Atheistic } \\
\text { evolution }\end{array}$ & $\begin{array}{l}\text { Life emerged from non-living particles and then all current forms } \\
\text { evolved from these earlier forms. No deity has ever played any role in } \\
\text { the evolution of life on Earth. }\end{array}$ \\
\hline
\end{tabular}

To interpret data collected using the tool in terms of student changes in position, we wished to order the positions into a spectrum (Figure 1). The ordering was initially determined by considering each position on the basis of its biblical literalism, ranging from the most literal position, literal creationism, to the least literal, atheistic evolution. Based on the set of positions identified from the literature, we began by distinguishing those involving a notion of Creator God from those that did not (non-theistic evolution), then 
Student positions on evolution and creation

splitting those in the former group into those admitting evolutionary mechanisms under theistic control (divine creation) from those excluding evolutionary mechanisms (creationism). In the non-theistic group, atheistic evolution was situated to the right of agnostic evolution because of its explicit denial of the role of Creator God. In the divine creation group, theistic evolution involved a continued role of the God in directing evolution and was therefore judged more literal than deistic evolution - in which God is considered to have set evolution running but maintains no further involvement - because of explicit references in the Bible to God's continued involvement in life on Earth (e.g. Colossians 1:17 and Romans 1:20). In the creationism group, we based our ordering on the extent to which positions were consistent with evolutionary evidence (even if not theory). Literal creationism takes a literal reading of the Bible and rejects all forms of evolution, and therefore was situated to the far left. Between higher genera created and humans only created, the latter accepted the existence of evolutionary processes for a larger range of species and was thus judged less literal. Finally, the ordering between humans only created and progressive creation proved the most difficult. Nonetheless, progressive creation explicitly accounted for evolutionary evidence regarding the gradual appearance of species, was consistent with evidence for the age of the Earth, and did not distinguish between humans and other species in ways that are not supported by evolutionary theory, and was ultimately judged less literal ${ }^{2}$. This ordering is consistent with the creation-evolution continuum originally proposed by Nelson (1986), and later used in Verhey (2005), with additional positions added.

In addition to representing biblical literalism, the spectrum can be thought of as representing scientific acceptability. In the latter case, interpretations of evolution towards the right of the spectrum correspond to greater acceptance of scientific evidence for evolution and increasing consonance with the underpinning assumptions of science (e.g. assumptions about the ordered nature of the universe and the possibility of naturalistic explanations). In addition to the full spectrum of eight positions, we also analysed our empirical data using a version consisting of seven positions from which atheistic evolution

\footnotetext{
${ }^{2}$ In the empirical data collected as part of this study, the humans only created position was selected by only two students, and the ordering of these two positions had little impact on the empirical findings.
} 
Student positions on evolution and creation

was removed. This additional examination was conducted because although atheistic evolution is associated with conceptions of evolution that are as scientifically tenable as those of agnostic evolution, it fails to capture some of the subtleties of contemporary philosophy of science. Because science is usually considered to be limited to investigating natural events through empirical investigation, using science to investigate the existence of God is, at best, highly problematic. Therefore, between these two positions, one might argue that agnostic evolution is more scientifically sophisticated; the reduced spectrum can therefore be thought of as an ordering of positions according to the extent to which they are scientifically defensible.

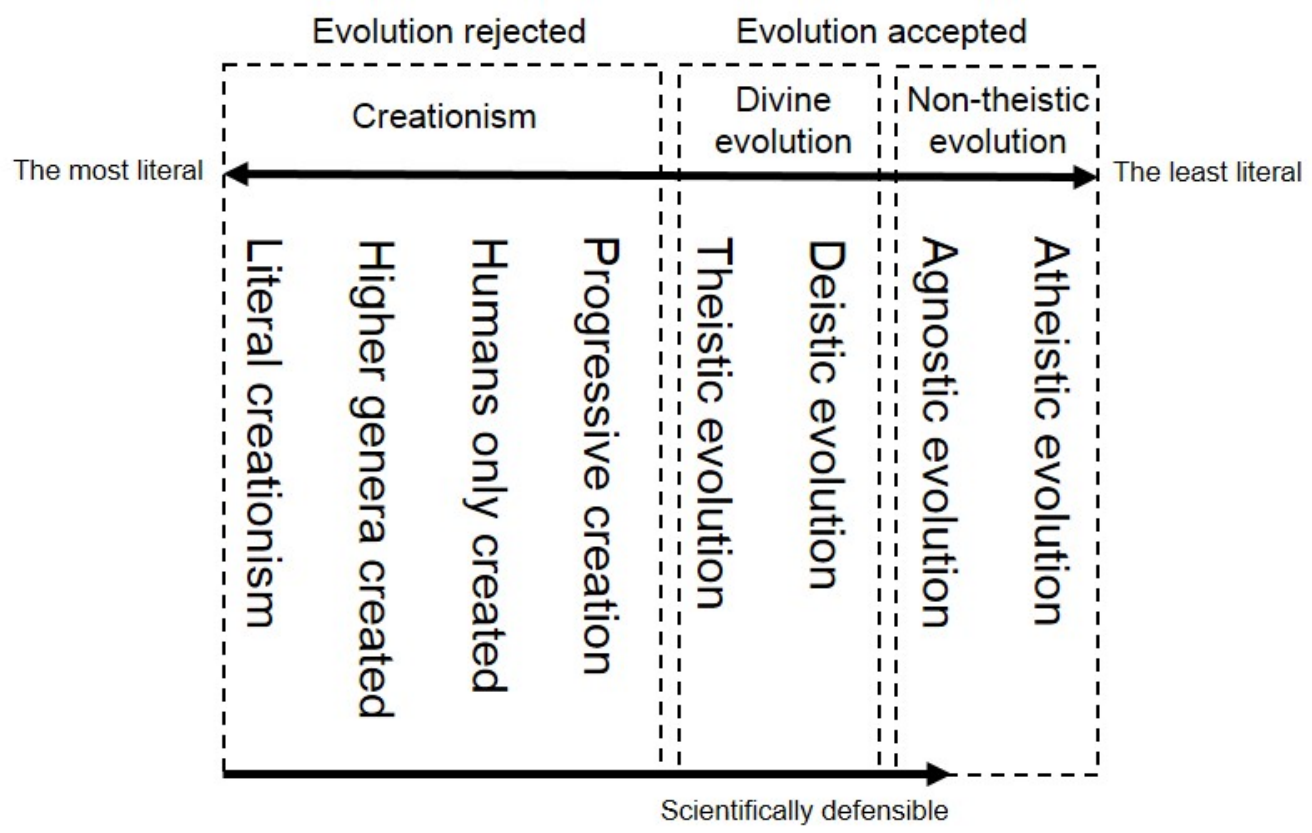

Figure 1: The spectrum of positions on the relationship between evolution and creation

\section{Student changes in positions}

Studies have provided some evidence of changes in student positions of the relationship between evolution and creation after taking a course related to evolutionary theory. For example, in one study, two out of twelve students in the US changed from either conflictual or unidentifiable to reconciliatory positions after taking an introductory biology course (McKeachie, Lin, \& Strayer, 2002). Fourteen out of fifteen students in a Christian university in the US are reported to have changed from literal creationism to 
Student positions on evolution and creation

theistic evolution after attending a course on evolution; one of these temporarily adopted humans only created ${ }^{3}$ and another progressive creation during the transition (Winslow, Staver, \& Scharmann, 2011). In addition, two Christian students in Thailand implied that they changed their positions from literal creationism to either progressive creation or deistic evolution during a course on biological evolution (Yasri \& Mancy, 2014).

Although these three studies report changes in positions and suggest that changes occurred in the direction positions in which evolution is accepted, the extent and direction of changes along a spectrum is not their main focus. Moreover, all these studies are based on a small number of student participants and lack support from statistical analyses. In a study with a larger number of participants ( $\mathrm{N}=66)$, Verhey (2005) provides further evidence of changes in position.. The spectrum used in this study comprises six positions: literal creationist, young earth creationist ${ }^{4}$, progressive creationist, theistic evolutionist, nontheistic evolutionist ${ }^{5}$ and atheistic evolutionist. The results show that 23 out of 38 students reported changes following an introductory biology course, in which they integrated discussions of biblical accounts on divine creation, Intelligent Design and the nature of science with the content and evidence of evolutionary theory. Among them, four out of six students who entered the course as literal creationists changed to young earth creationist (1), theistic evolutionist (2) and atheistic evolutionist (1). In addition, four out of 10 students who initially adopted young earth creationist changed to progressive creationist (1), theistic evolutionist (2) and agnostic evolutionist (1). However, Verhey’s study does not include statistical analysis and does not clearly distinguish between some of the positions we identified through our literature review. Specifically, Verhey (2005) appears to conflate higher genera created and humans only created in the position young earth creationist. In addition, there is no clear distinction between deistic evolution and theistic evolution. There is therefore call to investigate the extent to which students change their

\footnotetext{
${ }^{3}$ Note that the term used by Winslow et al. (2011) is young earth creationism (accepted non-human evolution).

${ }^{4}$ This position combines higher genera created and humans only created in the spectrum reported here.

${ }^{5}$ This position corresponds to agnostic evolution in the spectrum reported here.
} 
Student positions on evolution and creation

position and in what direction, using a more complete range of positions, and to test these changes statistically.

\section{Reasons for changes in positions}

In the literature to date, there is limited clarity on the factors that underpin student changes in position on the relationship between evolution and creation. Although Winslow et al. (2011) and Verhey (2005) suggest possible reasons, these were not provided by students but were inferred from the instructional interventions used in the studies. Proposed reasons include understanding the evidence for evolution, discussing different approaches to interpreting Genesis, recognising evolution as a non-salvation issue, and observing Christian role models who accept evolution (Winslow et al., 2011), alongside constructive discussions about the relationship between evolution and creation and the nature of science (Verhey, 2005).

Knowing the influence that students themselves believe underpin any change in their position is crucial for education as this should help teachers and lecturers communicate evolution in more diplomatic ways. Three key reasons for changes are referred to in the literature as influential: changes in understanding of the evidence for evolution (Downie \& Barron, 2000; Özay Köse, 2010; Southcott \& Downie, 2012; Winslow et al., 2011), changes in understanding of the relationship between science and religion (Ladine, 2009; Reiss, 2009; Yasri \& Mancy, 2014), and changes in religious beliefs (Dagher \& Boujaoude, 1997; Downie \& Barron, 2000). These reasons represent scientific, philosophical and religious reasons, respectively, and their relative roles have never been compared in a single study. We therefore included these three reasons in our study, not to suggest that these are the only influences, but to provide initial information for further in-depth studies.

\section{Methods}

We wished to maximise the number of positions on the relationship between evolution and creation present in the sample. Therefore we chose a religiously heterogeneous context, a Christian school in Thailand, in which debates over the relationship between science and religion are less politically charged than in the AngloSaxon world. The voluntary participants of this study were 125 high school final graders 
Student positions on evolution and creation

(M6), with mean age 17.58 years old and primarily of Buddhist (60\%) or Christian (34\%) religious orientation. These two groups of religious traditions are particularly interesting because they represent two contrasting ways of understanding the origin of life. While Buddhists typically separate spiritual life from scientific understanding, Christians more commonly view natural phenomena through a theistic lens based on their interpretations of the scripture. All participants had successfully passed a biology course on biological evolution lasting for three months.

The evolution course that participants had studied covered a range of topics including Darwinian evolution, evolutionary evidence (e.g. biogeography, fossil records, comparative morphology, comparative embryology and molecular biology), natural selection, the modern synthesis, microevolution, macroevolution, speciation and human evolution. The course was delivered in Thai by two biology teachers who adopted a perspective which aligns with the contrast view of the relationship between science and religion (Yasri and Mancy, 2014). More specifically, at the beginning of the course, the teachers introduced their students the differences between science and religion (Christianity), focusing on the different ways of learning about the world through religious and scientific endeavours. Having done this, the teachers explained that they respect other views on the ways in which science and religion can be related. For the rest of course, the teachers focused their instruction on evolutionary science, initiating class discussions where appropriate and explaining how scientific explanations can be drawn from the evidence. In addition, while teaching the key concepts of evolution, they tried to integrate these with other biological topics such as taxonomy, physiology and anatomy in order to highlight evolution as a central theme for understanding the biological world.

For the purposes of data collection, participants were asked to complete a questionnaire distributed about a week after the end of the course. The questionnaire included two questions of direct relevance to the current study as part of a larger survey (the full questions are provided in Appendix). In the first of these, they were presented with the eight statements representing the positions on the relationship between evolution and creation. They were asked to respond to the positions twice: firstly to select a single position they took before undertaking the course, and secondly, a single position they took at the end of the course (the question also included an "other" position for them to describe 
Student positions on evolution and creation

a position not listed). In the second question, they were asked to rate their level of agreement in a Likert format with three statements relating to the reasons for any changes; a blank space was provided for them to fill in reasons that were not mentioned.

The questionnaire used for data collection was translated into Thai from the original English version originally using a literary approach in which meaning, word order and expressions were carefully translated by the first author. The accuracy of translation was then checked by two Thai science educators who were fluent in both Thai and English. The readability of the translation was then improved by a teacher of science and mathematics who was the Head the academic department for these subjects and a teacher of religious education who was Head of the corresponding department at the participating school during the semester when the data collection took place.

In the next section, descriptive statistics are used to present the distribution of student positions on the relationship between evolution and creation, as well as overall patterns of changes in positions compared between before and after taking the course. Positions were treated as an ordinal variable; because the assumptions for the t-test were not met, changes were assessed using a Wilcoxon signed-rank test to assess the magnitude and direction of changes ${ }^{6}$. Reasons for changes based on the Likert-scale statements were analysed by examining the ratio of students agreeing versus disagreeing with each reason. Finally, a statistical test of the association between the magnitude of change and the strength of agreement with three reasons, both treated as ordinal variables, was conducted using a Spearman rank correlation test.

\section{Results}

The empirical data show that the research tool we developed is appropriate for assessing student positions on the relationship between evolution and creation. Every position was selected by at least one student to represent their position either before or after the evolution course. As shown in Figure 2, students tended to select more polarised positions before taking the course. Initially, almost 30\% selected one of the creationist positions

\footnotetext{
${ }^{6}$ To do this, we assumed a continuous latent variable underlying the named positions, specifically that of the relative level of acceptance on a continuum from biblical literalism to full acceptance of evolutionary explanations.
} 
Student positions on evolution and creation

whereas about 38\% selected either agnostic evolution or atheistic evolution. Less than $10 \%$ were attracted to theistic evolution and deistic evolution. The largest proportion of the students selected I don't know as the best description of their position before taking the course.

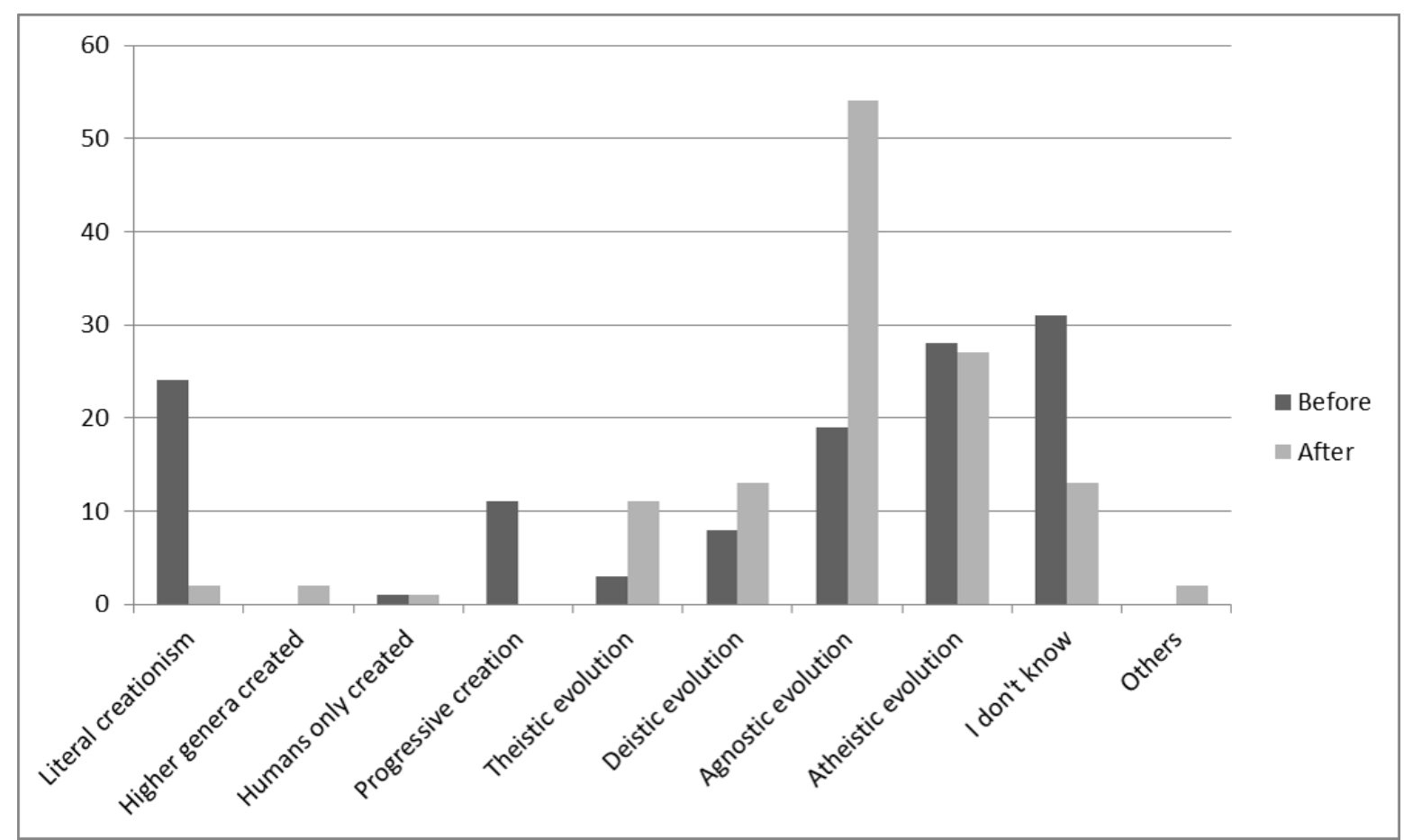

Figure 2: Distribution of positions on the relationship between evolution and creation before and after the course on evolution (raw frequencies)

After the course, subtle but common changes in student positions were observed (96 out of 125 individuals changed their position; Table 3). Specifically, among those who initially chose literal creationism, only $8 \%$ selected the same position, while the others had changed to more scientifically defensible positions including theistic evolution (25\%), deistic evolution (21\%) and agnostic evolution (30\%); 4\% changed more radically to the least literal position, atheistic evolution. A similar pattern was found among students initially selecting progressive creation who all took theistic evolution or deistic evolution positions (46\%) or agnostic evolution (54\%) by the end of the course. 
Running head: Student positions on evolution and creation

Table 3: Student changes in positions on the relationship between evolution and creation (positions taken before the course are in rows; and positions taken after in columns)

\begin{tabular}{|c|c|c|c|c|c|c|c|c|c|c|c|c|}
\hline & \multicolumn{9}{|c|}{ Positions taken after the course } & \multirow{3}{*}{ Total } \\
\hline & & & \multicolumn{3}{|c|}{ Creationism } & \multicolumn{2}{|c|}{ Divine evolution } & \multicolumn{2}{|c|}{$\begin{array}{l}\text { Non-theistic } \\
\text { evolution }\end{array}$} & \multirow[b]{2}{*}{$\begin{array}{l}\text { I don’t } \\
\text { know }\end{array}$} & \multirow[b]{2}{*}{ Others } & \\
\hline & & & $\begin{array}{c}\text { Literal } \\
\text { creationis } \\
\mathrm{m}\end{array}$ & $\begin{array}{l}\text { Higher } \\
\text { genera } \\
\text { created }\end{array}$ & $\begin{array}{l}\text { Humans } \\
\text { only } \\
\text { created }\end{array}$ & $\begin{array}{c}\text { Theistic } \\
\text { evolution }\end{array}$ & $\begin{array}{c}\text { Deistic } \\
\text { evolution }\end{array}$ & $\begin{array}{l}\text { Agnostic } \\
\text { evolution }\end{array}$ & $\begin{array}{l}\text { Atheistic } \\
\text { evolution }\end{array}$ & & & \\
\hline \multirow{16}{*}{ 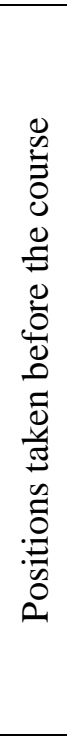 } & \multirow{6}{*}{ 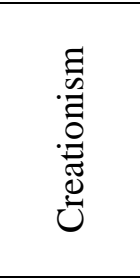 } & \multirow{2}{*}{$\begin{array}{c}\text { Literal } \\
\text { creationism }\end{array}$} & 2 & 1 & 1 & 6 & 5 & 7 & 1 & 1 & & 24 \\
\hline & & & $8.3 \%$ & $4.2 \%$ & $4.2 \%$ & $25.0 \%$ & $20.8 \%$ & $29.2 \%$ & $4.2 \%$ & $4.2 \%$ & & $100.0 \%$ \\
\hline & & \multirow{2}{*}{$\begin{array}{c}\text { Humans only } \\
\text { created }\end{array}$} & & & & & 1 & & & & & 1 \\
\hline & & & & & & & $100.0 \%$ & & & & & $100.0 \%$ \\
\hline & & \multirow{2}{*}{$\begin{array}{l}\text { Progressive } \\
\text { creation }\end{array}$} & & & & 1 & 4 & 6 & & & & 11 \\
\hline & & & & & & $9.1 \%$ & $36.4 \%$ & $54.5 \%$ & & & & $100.0 \%$ \\
\hline & \multirow{4}{*}{ 蛋菩 } & \multirow{2}{*}{$\begin{array}{l}\text { Theistic } \\
\text { evolution }\end{array}$} & & & & & 1 & 1 & 1 & & & 3 \\
\hline & & & & & & & $33.3 \%$ & $33.3 \%$ & $33.3 \%$ & & & $100.0 \%$ \\
\hline & & \multirow{2}{*}{ Deistic evolution } & & 1 & & & & 5 & 2 & & & 8 \\
\hline & & & & $12.5 \%$ & & & & $62.5 \%$ & $25.0 \%$ & & & $100.0 \%$ \\
\hline & \multirow{4}{*}{ 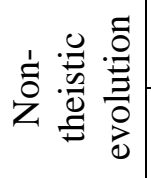 } & \multirow{2}{*}{$\begin{array}{l}\text { Agnostic } \\
\text { evolution }\end{array}$} & & & & & & 12 & 4 & 3 & & 19 \\
\hline & & & & & & & & $63.2 \%$ & $21.1 \%$ & $15.8 \%$ & & $100.0 \%$ \\
\hline & & \multirow{2}{*}{$\begin{array}{l}\text { Atheistic } \\
\text { evolution }\end{array}$} & & & & 1 & & 15 & 9 & 3 & & 28 \\
\hline & & & & & & $3.6 \%$ & & $53.6 \%$ & $32.1 \%$ & $10.7 \%$ & & $100.0 \%$ \\
\hline & \multirow{2}{*}{\multicolumn{2}{|c|}{ I don’t know }} & & & & 3 & 2 & 8 & 10 & 6 & 2 & 31 \\
\hline & & & & & & $9.7 \%$ & $6.5 \%$ & $25.8 \%$ & $32.3 \%$ & $19.4 \%$ & $6.5 \%$ & $100.0 \%$ \\
\hline \multirow{2}{*}{\multicolumn{3}{|c|}{ Total }} & 2 & 2 & 1 & 11 & 13 & 54 & 27 & 13 & 2 & 125 \\
\hline & & & $1.6 \%$ & $1.6 \%$ & $0.8 \%$ & $8.8 \%$ & $10.4 \%$ & $43.2 \%$ & $21.6 \%$ & $10.4 \%$ & $1.6 \%$ & $100.0 \%$ \\
\hline
\end{tabular}


Running head: Student positions on evolution and creation

The Wilcoxon signed-rank test was used to compare student positions before and after taking the course, across the spectrum of the full eight positions (including atheistic evolution). There was a significant difference in student positions $(Z=-5.0, p<0.01, N=87$, two-sided) of around 2 positions (estimated median difference), indicating a lesser degree of literalness or greater acceptance of evolution. The same analysis was carried out for Buddhist and Christian students separately, showing that changes for Christian students after taking the course were statistically towards the right end of the spectrum by about 3.5 positions ( $\mathrm{Z}=-4.5, \mathrm{p}<0.01, \mathrm{~N}=38$, two-sided). In contrast, there was no significant change among the Buddhist sample ( $\mathrm{Z}=-1.8, \mathrm{p}=0.07, \mathrm{~N}=43$, two-sided) as many students changed from atheistic evolution to agnostic evolution, cancelling out changes in the other direction.

In order to examine how individual students changed positions within the spectrum of positions excluding atheistic evolution, those who selected atheistic evolution either before or after taking the course were excluded. Tests showed that there was still a significant difference in students' positions before and after the course $(Z=-5.2, p<0.01$, $\mathrm{N}=54$, two-sided). This result suggests that in this group students tended to move towards more scientifically defensible positions by about 3.5 positions. This number is larger than the one in the previous calculation because changes to the right are compensated by those changing from atheistic evolution to agnostic evolution (i.e. to the left) in the previous analysis. This statistically significant shift was also found among the Christian sample, who tended to change towards more scientifically defensible positions $(Z=-4.7, p<0.01, N=35$, two-sided). However, there was no significant change among the Buddhist sample ${ }^{7}$.

In the analysis of reasons for changes of position, the (largely positive) ${ }^{8}$ changes were self-reported to be influenced by changes in understanding of the evidence for evolution as well as ways of relating science and religion, rather than changes in religious beliefs (Table 4). Respectively, over $60 \%$ and almost $50 \%$ of the participants agreed or

\footnotetext{
${ }^{7}$ One of the assumptions of the Wilcoxon signed-rank test is that the distribution of 'before-after' differences should be symmetric. Because it was difficult to determine whether this assumption was met for some tests, we conducted robustness testing using the sign test, finding that all qualitative conclusions reported for the Wilcoxon signed-rank test still held. We also repeated these tests combining the positions that had been hardest to order (humans only created and progressive creation) and found the results to be robust.

${ }^{8}$ Two respondents who reported changes towards more literal creation positions were also included in this analysis.
} 
Student positions on evolution and creation

strongly agreed with the statement that this resulted from changes in understanding of the evidence and the relationship between science and religion, whereas only 35\% agreed that this was due to changes in their religious beliefs. In contrast, the students tended to disagree that their change in position resulted from changing their religious beliefs (27\%).

Table 4: Student reasons for changes in position

\begin{tabular}{|c|c|c|c|c|c|c|c|}
\hline Samples & Reasons for changing & 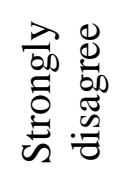 & 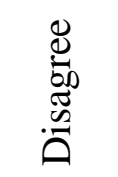 & 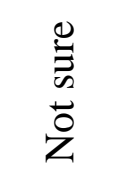 & 峁 & 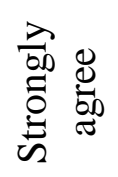 & $A: D$ \\
\hline \multirow{3}{*}{$\begin{array}{c}\text { All } \\
(\mathrm{N}=96)\end{array}$} & Understanding of evidence & $0.0 \%$ & $5.2 \%$ & $33.3 \%$ & $54.2 \%$ & $7.3 \%$ & 12:1 \\
\hline & Science-religion relationship & $1.0 \%$ & $6.3 \%$ & $44.8 \%$ & $37.5 \%$ & $10.4 \%$ & $7: 1$ \\
\hline & Religious beliefs & $16.7 \%$ & $10.4 \%$ & $37.5 \%$ & $30.2 \%$ & $5.2 \%$ & $1: 1$ \\
\hline \multirow{3}{*}{$\begin{array}{l}\text { Christian } \\
(\mathrm{N}=35)\end{array}$} & Understanding of evidence & $0.0 \%$ & $5.7 \%$ & $40.0 \%$ & $48.6 \%$ & $5.7 \%$ & $10: 1$ \\
\hline & Science-religion relationship & $0.0 \%$ & $2.9 \%$ & $45.7 \%$ & $45.7 \%$ & $5.7 \%$ & 18:1 \\
\hline & Religious beliefs & $40.0 \%$ & $14.3 \%$ & $11.4 \%$ & $31.4 \%$ & $2.9 \%$ & $1: 2$ \\
\hline \multirow{3}{*}{$\begin{array}{c}\text { Buddhist } \\
(\mathrm{N}=57)\end{array}$} & Understanding of evidence & $0.0 \%$ & $5.3 \%$ & $28.1 \%$ & $57.9 \%$ & $8.8 \%$ & 13:1 \\
\hline & Science-religion relationship & $1.8 \%$ & $8.8 \%$ & $43.9 \%$ & $31.6 \%$ & $14.0 \%$ & $4: 1$ \\
\hline & Religious beliefs & $3.5 \%$ & $8.8 \%$ & $52.6 \%$ & $28.1 \%$ & $7.0 \%$ & $3: 1$ \\
\hline
\end{tabular}

The far right column of Table 4 shows the ratio of agreement to disagreement (A:D) with the reasons for change, and shows a clearer trend for the results described above. In the full sample, for every 12 students who agreed that their change had been influenced by changes in their understanding of the evidence for evolution, and for every seven who agreed that their change had been influenced by changes in their understanding of the relationship between science and religion, there was one who disagreed. This pattern was even more distinctive when focusing on the Christian sample, where the highest ratio of agreement to disagreement was found for the relationship between science and religion (18:1), followed by understanding of the evidence (10:1); in contrast, for every student who agreed with changes in religious beliefs, there were two who disagreed.

A slightly different result was found among Buddhist students who appeared to show stronger agreement with the statement about changes in their understanding of the evidence (13:1). However, the ratios are more equivalent when concerning changes in 
Student positions on evolution and creation

religious beliefs (3:1) and in the relationship between science and religion (4:1). Both understanding of the evidence for evolution and the changes in understanding of the relationship between science and religion were important factors for Christian students to reformulate their positions about the origin of life and biodiversity, whereas Buddhist students appeared to attribute changes in position almost solely to changes in their understanding of the evidence. The results reveal that changes in religious beliefs are perceived by Christian participants to have less impact on their changes in positions than is the case for Buddhist students

We also examined the relationship between the strength of agreement with the three reasons for changes and the magnitude of change, by which we mean the number of positions changed along the spectrum. For example, a student who took a literal creationism position before taking the course and an agnostic evolution position at the end obtains a +6 score in relation to the eight positions proposed. Focusing on the full range of the positions, a Spearman's rank order correlation was calculated to determine the relationship between the magnitude of change and level of agreement with each reason. The analysis revealed a moderate negative correlation between the magnitude of change and level of agreement with changes in religious beliefs (all participants reporting a change between the 8 ordered positions and providing reasons $\mathrm{N}=87 ; r_{s}(85)=-0.307, \mathrm{p}=0.014$ ). However, there was no significant correlation between the magnitude of change and the other two reasons. This suggests that the larger the change towards the less literal positions, the less students agree that this was influenced by changes in their religious beliefs.

\section{Discussion}

In relation to the spectrum of positions on the relationship between evolution and creation, the empirical work carried out first shows that it is possible for high school level students to take any position in the spectrum, indicating that the inclusion of the eight positions is empirically valid. Previous studies focusing on a range of positions (Brem et al. 2003; Scott 2005; and Verhey, 2005) may therefore have missed changes in position because their spectrums were less fine-grained.. Distinctions between these positions, especially at the more literal end of the spectrum, are likely to be important in the classroom. For example, accepting evolution of non-human species but not humans is likely 
Student positions on evolution and creation

to have important implications for student understanding of areas such as evolutionary medicine, where both are invoked.

Although our spectrum is more complete than those in earlier work, it is important to note that that the philosophical literature contains a much broader range of conceptions (Peters 2007). For example, the spectrum used here contains only two positions in which there is no involvement of God. It also fails to capture concepts more closely aligned with pantheism (i.e. the belief that all things are divine) or panentheist (i.e. the belief that all things exist within God's being). Holders of these beliefs may not distinguish so sharply between the initial creation event and continuing evolutionary process, considering instead that evolution forms part of the work of creation. These understandings do not appear in the evolution education literature and we took the view that such fine distinctions would be unlikely to arise among high school students without formal philosophical or theological training. However, further exploration of these more nuanced positions with students of this age would certainly constitute an interesting extension to this work.

In relation to student changes in position, this study first provides the dataset that allows us to compare Christian to Buddhist students, giving us an indication of the extent to which positions and changes between them are religion-dependent. Among the Buddhist students, positions that were predominantly selected before taking the course were agnostic evolution and atheistic evolution. After taking the course, the pattern of shifts appeared to be from atheistic evolution to agnostic evolution. In contrast, among the Christian students, the creationism positions were the most common before taking the course. Their specific pattern of changes appeared to be in the direction of more scientifically defensible positions including theistic evolution, deistic evolution or agnostic evolution. The pattern shows that these changes are not simply occurring through student inconsistencies in completing the questionnaire. They are consistent with theoretical doctrinal positions of two different traditions of religious beliefs (i.e. the nontheistic tradition of Buddhism is associated with nontheistic evolution whereas the theistic religious tradition of Christianity is associated with theistic/deistic evolution). Further, one might consider the Buddhists as a "control group”, and the contrast between the groups providing further evidence that the changes found for Christian students are non-random.

We now focus on particular changes and their relationship with changes reported in the literature. Students taking a theistic evolution position before taking the course all 
Student positions on evolution and creation

changed their position towards the right end of the spectrum, ultimately adopting deistic evolution or agnostic evolution. In contrast, in Verhey's (2005) study, the majority of those initially subscribing to theistic evolution did not change their position. It is possible that the change detected in our work results from the clear distinction between theistic evolution and deistic evolution which is absent in Verhey's (2005) classification. In fact, one third of those initially subscribing theistic evolution in our study moved to deistic evolution. Any similar changes would have remained undetected in Verhey’s (2005) work.

An interesting pattern of student changes is found among those initially taking the non-theistic evolutionist positions. The majority of those initially subscribing to atheistic evolution (15 out of 24) moved towards agnostic evolution (one step to the left in the spectrum), a less 'scientistic' or more scientifically sophisticated position. This finding appears to be similar to that of Verhey (2005) in terms of the possibility of changes to the left from non-theistic evolution. However, the single student (of three) in Verhey's (2005) study changed in this direction ultimately adopted progressive creation.

We now consider responses from those initially adopting agnostic evolution. This study shows that about $63 \%$ of these participants maintained this position after taking the course. This is similar to the result from Verhey (2005) that shows that none of those initially adopting agnostic evolution $(\mathrm{n}=9)$ changed their position. Learning about evolutionary theory is unlikely to cause conflict with the worldview that these students adopt, and thus no change in position is required to integrate evolution with their existing beliefs.

Reflection on the limitations of the study served to highlight additional areas for future methodological development and investigation. Firstly, the validity of asking students to reflect upon a position taken at an earlier point in time requires some consideration. Verhey (2005) argues that the main alternative, using a protocol in which students complete the same questionnaire before and after the course, is problematic for positions on evolution and creation because this approach might introduce them to positions at the beginning of the course, in turn influencing their engagement with the course and associated learning materials. Any observed changes could then no longer be linked to the influence of the course. The course taken by the students involved in our work lasted 11 weeks, with the questionnaire completed in the week following course completion, 
Student positions on evolution and creation

requiring students to recall their position from only 12 weeks earlier, so this may not have been a problem.

As part of a larger study, we had also collected data on the position of students from the same school who had not yet studied the course on evolution, as they were one year younger than those involved in the main cohort. We used the responses of these students to validate the recalled 'before' positions of the main study participants. Mann-Whitney U tests were used to compare the relative ranking of positions taken by the younger students with both the 'before' and 'after' positions of the main study group. These tests did not detect a statistically significant difference between the younger group on the spectrum and the 'before' positions of the main study participants, for either Christian or Buddhist students $^{9}$. Comparing the younger students with the 'after' position of the main study participants resulted in qualitatively similar results to the 'before-after' changes described above, in which no significant difference was detected for Buddhist students but a significant difference, in the same direction and of a similar magnitude, was seen for Christian students. The finding that these results are qualitatively consistent with the tests conducted as part of the main study lends support to the validity of using the recall approach.

Nonetheless, it would be valuable for researchers to validate our findings by distributing the questionnaire twice, before and after a course on evolutionary biology, to compare the two protocols, ideally supplementing with interviews and a delayed post-test to check stability of positions beyond the period of the course. This approach would also be useful to clarify whether the relatively high number of students selecting as their initial position "I don't know" was because they had forgotten their initial position, or because they did not have one at this point in time. In our study, students were asked to indicate a single statement best capturing their position for each of the two time points. As a result, we were unable to analyse the case of students agreeing concurrently with multiple

\footnotetext{
${ }^{9}$ Although there were some differences in the distributions of positions when these were compared visually, the Mann-Whitney $U$ would not be expected to detect these because they affected the spread rather than the location of the distribution: specifically, positions in the younger group were slightly less polarised towards the ends of the spectrum than the 'before' positions of the main study group. The cause of this difference remains unknown and does not fundamentally affect our conclusions, but would be a valuable issue for consideration in future work.
} 
Student positions on evolution and creation

positions, or the strength of agreement with different positions. This approach facilitated data analysis, but it would be helpful to allow students to indicate the strength of agreement with multiple positions in future work as this would help to identify fine-grained nuances in their positions.

In relation to student reasons for changing position, students in this sample attributed changes to changes in their scientific knowledge (understanding of evidence for evolution) and to changes in their philosophical perspective (the relationship between science and religion), but not to changes in religious beliefs. In fact, the larger their change towards the right-hand end of the spectrum, the less they agreed that their religious beliefs had altered. Educational implications of this finding are that learning how evolution has been constructed through scientifically valid evidence may enable learners to perceive evolution in more sophisticated ways, leading to greater open-mindedness to learn and accept evolution (Ladine, 2009). In addition, learning that there are compatible ways in which science and religion can be related may avoid threats to their religious beliefs (Yasri \& Mancy, 2014). These two aspects may help students come to understand what science (and evolution) is and how it works, the main focus of teaching the nature of science. Importantly, this study provides confirmation of the claim that religious students can learn and accept evolution without experiencing insurmountable threats to their religious beliefs.

The proportion of students changing position is perhaps surprising as the evidence presented here demonstrates that changes can occur at a very high frequency (70\%). The evidence for common changes seems to be less clear in previous studies (McKeachie et al., 2002; Verhey, 2005). However, to date, it has been unclear whether this has been due to lack of change (i.e. nothing to detect) or due to measurement insensitivity. This study suggests that, using fine-grained instruments, it is possible to test quasi-experimentally whether particular teaching and learning approaches are more likely to lead to changes. Answers to these questions have, so far, evaded researchers in this area.

\section{Implications}

This study suggests that student positions on the relationship between biological evolution and biblical creation change primarily through changes in understanding of the evidence for evolution and the relationship between science and religion. One implication for biology teachers is that in order to assist students to learn evolution comfortably and 
Student positions on evolution and creation

successfully, it is important to introduce them to the evidence. We argue that teaching evolutionary theory through discussion of the body of evidence is not only important for developing student understanding of the core concepts of evolution, it also provides a backdrop against which students can formulate a decision on whether to accept evolution or not at the individual level. This is well aligned with the suggestion of Hokayem and BouJaoude (2008) who state that all students should recognise the importance of scientific evidence in making a decision about whether to accept evolutionary theory. This approach also has the advantage of exposing students to the nature of science and scientific inquiry, and avoids making evolution education appear as a kind of indoctrination in which teachers simply provide scientific facts.

In addition to focusing on discussion of the evidence, it might also be useful for pedagogical approaches to include discussion of the relationship between science and religion. This might be included at the beginning of the course in order for students to be aware of different views for relating the two perspectives, ideally before conflicts occur. This recommendation would address the problem which Winslow et al. (2011) raise when they note that average pupils are unaware of other positions on the relationship between scientific explanations of evolution and religious beliefs of divine creation, and tend to consider only a black-and-white relationship. By minimising possible conflicts, allowing students to see the diversity of views could also lead to more positive learning outcomes. If students can view the relationship positively, they may become more open to learn about evolutionary theory, supporting better scientific understanding. This suggestion is also supported by work such as that of Ingram and Nelson (2006) that reveals that students' attitudes towards evolution were positively related to their final grades.

In conclusion, this work provides a new research tool for future work in the field that is capable of detecting subtle changes in student positions on the relationship between evolution and creation. Our findings suggest that it is possible for such changes to occur at high frequency among students of high school age as they learn about evolution. The fact that the tool is quick and easy to use makes it plausible to investigate whether this finding generalises to different pedagogical approaches, to learners at other educational stages and to other cultural contexts, and makes it possible to conduct investigations with large student samples. We found that students attributed their changes in position to developments in their understanding of the evidence for evolution and the relationship between science and 
Student positions on evolution and creation

religion, but not to changes in their religious beliefs per se. Further investigations that focus more directly on reasons for changes in position would be valuable. For example, it would be helpful to know what kinds of evidence students find most convincing, and which particular examples help them make the most sense of evolutionary events and mechanisms. It would also be useful to see to what extent views on the relationship between science and religion influence student positions on the relationship between evolution and creation, perhaps using in-depth interviews to explore this in greater detail.

Appendix: The questionnaire

Which of the following best fit your view at the start of your studies and now?

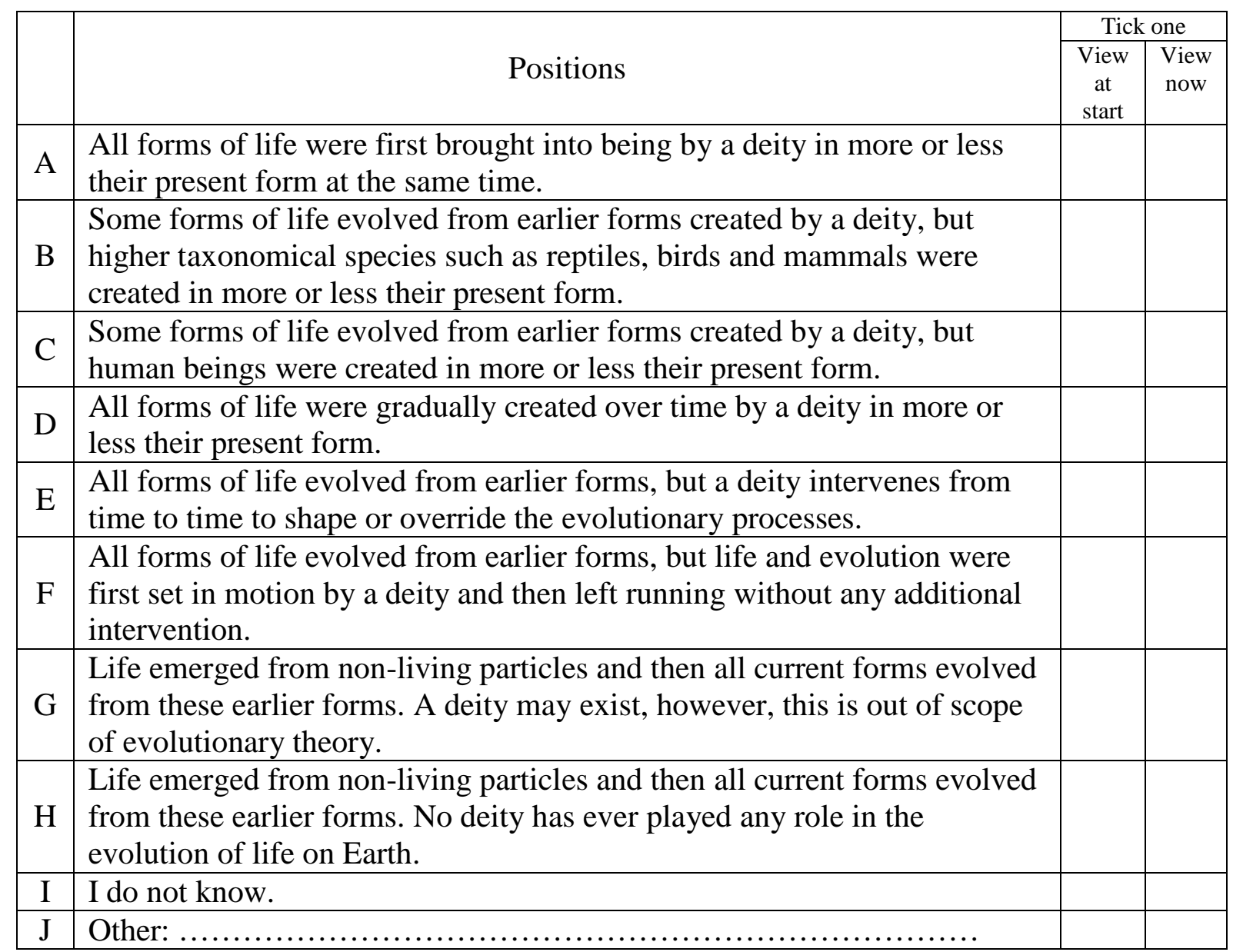

\section{References}

Alexander, D. (2009). Creation of evolution: Do we have to choose? Oxford: Monarch Books.

Brem, S. K., Ranney, M., \& Schindel, J. (2003). Perceived consequences of evolution: 
Student positions on evolution and creation

College students perceive negative personal and social impact in evolutionary theory. Science Education, 87(2), 181-206. doi: 10.1002/sce.10105

Collins, F. S. (2006). The Language of God: A Scientist Presents Evidence for Belief. New York: Free Press.

Dagher, Z. R., \& Boujaoude, S. (1997). Scientific views and religious beliefs of college students: The case of biological evolution. Journal of Research in Science Teaching, 34(5), 429-445. doi: 10.1002/(sici)1098-2736(199705)34:5<429::aid-tea2>3.0.co;2-s

Downie, J., \& Barron, N. (2000). Evolution and religion: Attitudes of Scottish first year biology and medical students to the teaching of evolutionary biology. Journal of Biological Education, 34(3), 139-146. doi: 10.1080/00219266.2000.9655704

Hokayem, H. \& Boujaoude, S. 2008. College students' perceptions of the theory of evolution. Journal of Research in Science Teaching, 45, 395-419.

Ingram, E. L. \& Nelson, C. E. 2006. Relationship between achievement and students' acceptance of evolution or creation in an upper-level evolution course. Journal of Research in Science Teaching, 43, 7-24.

Ladine, T. (2009). Attitudes of students at a private Christian liberal arts university toward the teaching of evolution. Evolution: Education and Outreach, 2(3), 386-392. doi: 10.1007/s12052-009-0147-y

Nelson, C. E. (1986). Creation, Evolution, or Both? A Multiple Model Approach. In: Hanson, R. (ed.) Science and Creation. New York: Macmillan.

McKeachie, W., Lin, Y., \& Strayer, J. (2002). Creation vs. evolution beliefs: Effects on learning biology. The American Biology Teacher,, 64(3), 189-192. doi: 10.1662/00027685(2002)064[0189:CVEBEO]2.0.CO;2

Özay Köse, E. (2010). Biology students“ and teachers” religious beliefs and attitudes towards theory of evolution. Hacettepe Universitesi Journal of Education, 38, 189-200.

Reiss, M. J. (2009). The relationship between evolutionary biology and religion. Evolution, 63, 1934-1941. doi: 10.1111/j.1558-5646.2009.00714.x

Scott, E. C. (2005). Evolution vs Creationism: An Introduction. California: University of California Press.

Smith, M. (2010). Current status of research in teaching and learning evolution: I. philosophical/epistemological issues. Science \& Education, 19(6-8), 523-538. doi: 10.1007/s11191-009-9215-5 
Student positions on evolution and creation

Southcott, R., \& Downie, J. R. (2012). Evolution and religion: Attitudes of Scottish bioscience students to the teaching of evolutionary biology. Evolution: Education and Outreach, 5(2), 301-311. doi: 10.1007/s12052-012-0419-9

Verhey, S. D. (2005). The effect of engaging prior learning on student attitudes toward creationism and evolution. BioScience, 55(11), 996-1003. doi: 10.1641/00063568(2005)055[0996:TEOEPL]2.0.CO;2

Winslow, M. W., Staver, J. R., \& Scharmann, L. C. (2011). Evolution and personal religious belief: Christian university biology-related majors' search for reconciliation. Journal of Research in Science Teaching, 48(9), 1026-1049. doi: 10.1002/tea.20417

Yasri, P., \& Mancy, R. (2014). Understanding student approaches to learning evolution in the context of their perceptions of the relationship between science and religion. International Journal of Science Education, 36(1), 24-45. doi: 10.1080/09500693.2012.715315

Yasri, P., Arthur, S., Smith, M. U., \& Mancy, R. (2013). Relating science and religion: An ontology of taxonomies and development of a research tool for identifying individual views. Science \& Education, 22(10), 2679-2707. doi: 10.1007/s11191-013-9623-4 